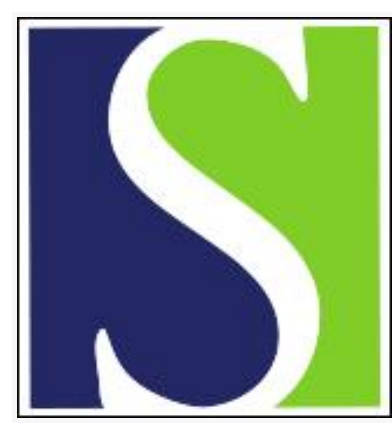

Scand J Work Environ Health 1994;20(1):1-12

https://doi.org/10.5271/sjweh.1435

Issue date: $01 \mathrm{Feb} 1994$

Methodological approach to the evaluation of neurotoxicity data and the classification of neurotoxic chemicals.

by Simonsen L, Johnsen H, Lund SP, Matikainen E, Midtgard U, Wennberg $\mathrm{A}$

Affiliation: National Institute of Occupational Health, Copenhagen, Denmark.

This article in PubMed: www.ncbi.nlm.nih.gov/pubmed/8016593

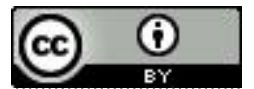




\title{
Methodological approach to the evaluation of neurotoxicity data and the classification of neurotoxic chemicals
}

\author{
by Leif Simonsen, PhD, ${ }^{1}$ Helge Johnsen, ${ }^{2}$ Søren P Lund, PhD, ${ }^{1}$ Esko Matikainen, MD, ${ }^{3}$ \\ Uffe Midtgård, DSc, ${ }^{1}$ Arne Wennberg, MD ${ }^{4}$
}

\begin{abstract}
SIMONSEN L, JOHNSEN H, LUND SP, MATIKAINEN M, MIDTGÅRD U, WENNBERG A. Methodological approach to the evaluation of neurotoxicity data and the classification of neurotoxic chemicals. Scand J Work Environ Health 1994;20:1-12. This text is the result of the authors' involvement in a working group on criteria for the identification and classification of neurotoxic chemicals. (The work of the group does not necessarily represent the official stand of the affiliated institutes.) A definition of neurotoxicity and criteria for evaluating studies dealing with neurotoxicology are presented. The evaluation is a stepwise process that ends with assigning the chemicals to groups depending on the available evidence for neurotoxicity (ie, neurotoxic, probably neurotoxic, possibly neurotoxic, probably not neurotoxic, or not classifiable). Finally, the description of the potency of neurotoxic chemicals is briefly discussed. The model has been tested by evaluating selected research papers on the following 10 chemicals: manganese, aluminum, tetrahydrofuran, cyclohexanone, dichlorvos, trichloroethylene, formaldehyde, tri-ortho-cresyl phosphate, $n$-hexane, and vinyl chloride. There was sufficient evidence for classifying five of the ten chemicals (aluminum, manganese, $n$-hexane, trichloroethylene, tri-ortho-cresyl phosphate) as definitely neurotoxic to humans, and three were considered to be possibly neurotoxic to humans (dichlorvos, tetrahydrofuran, vinyl chloride). Cyclohexanone and formaldehyde were not classifiable according to the model.
\end{abstract}

Key terms: guidelines, hazard assessment, neurotoxicity criteria, neurotoxicity testing, regulatory toxicology, review.

The human nervous system is one of the most complex organs in terms of both structure and function. It is composed of more than 100 billion cells of different types, such as astrocytes, neurons, and Schwann cells. Each neuron has numerous synapses to other neurons, sensory cells, muscle cells, or glands. More than 100 different substances are used as neurotransmitters, and they vary in chemical structure from simple amino acids (eg, glutamic acid) to peptides such as somatostatin and galanin. Furthermore, the function of the nervous system is plastic, and therefore the response of the nervous system to sensory input is dependent on previous input $(1-4)$.

The complexity of the nervous system is reflected in the wide variety of toxic actions that can be exerted upon it by hazardous chemicals and by the large number of symptoms and signs associated with these actions. Apathy, dementia, coma, hyperactivity, irritability, paralysis, sensory dysfunction, spasticity, tremor, cramps, and weight loss are all signs

National Institute of Occupational Health, Denmark.

2 Norwegian Defence Research Establishment, Kjeller, Norway.

3 Institute of Occupational Health, Helsinki, Finland.

4 National Institute of Occupational Health, Solna, Sweden.

Reprint requests to: Dr $\mathrm{L}$ Simonsen National Institute of Occupational Health, Lersø Parkallé 105, DK-2100 Copenhagen, Denmark. or symptoms associated with neurotoxicity in humans $(5-8)$.

Although the blood-brain barrier protects the major parts of the central nervous system from many toxic substances, there are areas of the brain where this protection is less effective. These areas include the pineal body, hypothalamus, and the autonomic ganglia (9). Furthermore, several noxious substances, particularly those that are soluble in lipids, are able to cross the blood-brain barrier (10).

Neurotoxic chemicals are found in the workplace, in homes, and in the environment. Several examples exist of outbreaks of neuronal diseases due to environmental pollution and incidents of contamination of food or beverages. Chemicals that are generally considered to be neurotoxic include various pesticides, solvents, and metals or organometal compounds (11). Furthermore, some drugs are considered neurotoxic under occupational circumstances.

Public awareness of the potentially harmful effects of chemicals and drugs on the nervous system has increased over the last few decades $(5,8,12,13)$. Several agencies and groups in different countries have therefore started to recommend guidelines and "test batteries" for screening chemicals for their neurotoxic potential $(6,13-17)$, and a core protocol for performing epidemiologic studies has been prepared by the World Health Organization (18).

Although it is extremely important to establish screening tests for new chemicals and guidelines for 
conducting tests, it is equally important to provide a basic definition of neurotoxicity and guidelines for evaluating existing data on neurotoxicity. The evaluation of data is usually the first step in the process of evaluating neurotoxicity. This step may later be followed by recommendations for further animal testing, leading to a complete estimation of neurotoxicity, if the existing data are found inconsistent or insufficient for evaluation.

The objectives of the present work were to set up a definition of neurotoxicity and to develop a model to be used for evaluating studies dealing with toxic effects of chemicals on the nervous system of animals and humans. The described model can serve to classify chemical agents according to their neurotoxic effect and potency; this is an important step in risk assessment and in the prevention or minimization of human exposure to hazardous chemicals. The present paper should therefore primarily be looked upon as a contribution to the risk assessment of occupational and environmental exposure to chemicals.

\section{Definition of neurotoxicity}

Several definitions of neurotoxicity can be found in the literature. While some consider any adverse effect on the nervous system as neurotoxicity, others suggest a differentiation between reversible and irreversible effects $(14,19)$. Furthermore, the definition of neurotoxicity can vary depending on viewpoint and field of interest. A toxicologist may use neurotoxicity to describe biochemical or physiological abnormalities induced in the nervous system by the chemical under study. In this context, neurotoxicity is often envisaged as a universal feature having specific effects on a neuronal cell. On the other hand, occupational health personnel and specialists in occupational medicine often characterize neurotoxicity as a cause of human disorder due to exposure to some specific chemical, or a mixture of chemicals. These two views of neurotoxicity are not mutually exclusive, and both have to be considered in the definition.

Because of conceptual differences as to the meaning of the word neurotoxicity, it was decided to use the following definition: neurotoxicity refers to the capability of inducing adverse effects in the central nervous system, peripheral nerves, or sense organs. A chemical is considered to be neurotoxic if it is capable of inducing a consistent pattern of neural dysfunction or lesion in the nervous system.

Furthermore, a crude distinction can be drawn between reversible neurotoxic effects and irreversible neurotoxic effects. Reversible effects are usually due to temporary functional changes in the nervous system. They occur mainly in experimental or accidental solvent or pesticide exposure episodes. In this context, such totally reversible effects are not considered neurotoxic. Irreversible neurotoxic effects generally involve structural changes with degeneration of the nerve cells. However, there are examples of lasting functional changes without any apparent morphological abnormalities (20).

Neurotoxicity is a general phenomenon, and neurotoxic changes in structure or function can therefore be demonstrated in humans as well as in animals. Such changes are due to the fact that all neurotoxins exert their action at the molecular level of nerve cells. However, demonstration of neurotoxicity in this sense does not necessarily mean that the chemical in question constitutes a risk to humans. There are often significant species differences in the susceptibility of the nervous system of animals to various chemicals. For instance, 1-methyl-4-phenyl1,2,3,6-tetrahydropyridine (MPTP) is extremely neurotoxic to humans but not to rats $(21)$. The situation can also be the opposite in that some animals are much more vulnerable to chemicals than humans. However, for practical reasons, evidence of a neurotoxic action by a specific chemical in one or more animal species may suggest that the same chemical is neurotoxic in humans. Even if general animal neurotoxicity can be demonstrated, extrapolation to humans should be made with caution.

Neurotoxicity is generally manifested as a continuum of symptoms and effects, which among other things depend on the nature of the chemical, the dose, and the duration of exposure. The different strengths of effects recognized for neurotoxicity are shown in table 1 . The severity of the observed effects, as well as the evidence of neurotoxicity, increases through levels 1 to 6 . Short-term or low-dose exposure to a neurotoxic chemical can result in subjective symptoms such as headache and dizziness, but the effect is usually reversible. With increasing dose, neurological changes can appear, and eventually irreversible morphological changes are produced. However, doses near or above those resulting in the death of animals should not be taken into consideration when the neurotoxicity of chemicals is evaluated. Furthermore, at a given dose, it should be ascertained that the nervous system is the primary target of the chemical.

The degree of abnormality needed for implying neurotoxicity for a chemical agent is a controversial issue which somehow depends on subjective evaluations. According to the definition, and for the present purpose, we suggest that a chemical be considered neurotoxic if there is well documented evidence for lasting effects on level 4,5 , or 6 in table 1 . In addition, reports on biochemical changes (level 3) should be taken as evidence for neurotoxicity in those cases in which a structurally related chemical has been proved neurotoxic with a known biochemical mechanism, which can be used as an assay for neurotoxicity, for instance, in the case of the organophosphates, for which the neurotoxic esterase (NTE) activity test can be used as a toxicity test (22). In all other cases of biochemical changes, 
Table 1. Different signs of neurotoxicity. The order of listing represents decreasing strength in the evidence of neurotoxicity.

\begin{tabular}{|c|c|c|}
\hline Level & Effect & Explanation/examples \\
\hline 6 & Morphological changes & Cell death and axonopathy, as well as subcellular morphological changes \\
\hline $5^{a}$ & Neurological changes & Findings from neurological examinations of single individuals \\
\hline 4 & $\begin{array}{l}\text { Physiological/behavioral } \\
\text { changes }\end{array}$ & $\begin{array}{l}\text { Experimental findings in groups of animals or humans as changes in evoked } \\
\text { potentials and electroencephalography or changes in psychological and } \\
\text { behavioral tests }\end{array}$ \\
\hline 3 & Biochemical changes & $\begin{array}{l}\text { Changes in relevant biochemical parameters (eg, transmitter level, content } \\
\text { of glial fibrillary acidic protein, or enzyme activities) }\end{array}$ \\
\hline $2^{a}$ & $\begin{array}{l}\text { Irreversible, subjective } \\
\text { symptoms }\end{array}$ & Symptoms not verified by a neurological examination or measurements \\
\hline $1^{\mathrm{a}}$ & $\begin{array}{l}\text { Reversible, subjective } \\
\text { symptoms }\end{array}$ & Symptoms not verified by a neurological examination or measurements \\
\hline
\end{tabular}

a Humans only.

in vitro tests and quantitative structure activity relationship (QSAR) analysis should be looked upon only as supporting data. Irreversible subjective symptoms in humans should be supported by experimental data.

Table 1 therefore reflects the weight of evidence provided by different signs of neurotoxicity. The higher the value of the evidence, the higher the certainty that the chemical is neurotoxic. Both human and animal data can, and must, be used in this evaluation. However, the effects and neurotoxic potentials of a chemical vary greatly between species, primarily due to differences in kinetics, but also due to differences in mechanisms of action and sensitivity. Furthermore, the effects and neurotoxic potentials of different chemicals vary too, and the table should be considered only as a rough classification of neurotoxic effects.

\section{Screening tests for neurotoxicity}

Rather than providing an overview of the methods used in neurotoxicity studies, this section deals with some important issues in neurotoxicity testing. For a detailed review of methods in neurotoxicity, the reader is referred to the comprehensive accounts in the literature $(6,18,23)$.

Real or potential hazard to the nervous system is difficult to assess because of the complexity of the nervous system. Some of the problems in hazard assessment are associated with the large number of targets for toxic action in the nervous system, and some are related to an incomplete understanding of how the results should be interpreted, as, for instance, with the changed activity in open field tests. Furthermore, some neurotoxic effects may be masked by the plasticity of the nervous system. It is clear, therefore, that normally no single test will suffice to characterize the hazard of a chemical to the nervous system, and it is impossible to envisage a simple specific test method of universal validity for neurotoxicity screening. In other words, the use of stereotyped predetermined tests is indeed inappropriate in neurotoxicology more than in any other branch of toxicology (13).

Ideally, a predetermined neurotoxicity test of a novel compound requires both short-term and longterm exposure to the compound, a sufficient number of species to compensate for possible interspecies variation, and exposure of neonates, as well as adults. Furthermore, no single experimental technique is capable of detecting all possible neurotoxic effects. The predetermined tests should therefore be tailored for the compound in question or should constitute a battery of different techniques, such as behavioral, histological, electrophysiological, neurological, and biochemical studies. Moreover, they should be performed on different species for different genders and ages and at different dose levels.

When compounds with hitherto unknown properties are tested, a tier testing approach is generally accepted as the most appropriate strategy. In tier testing, each successive stage should be designed to answer increasingly specific questions about the toxicity of a chemical $(6,24-26)$. At first, "simple" methods of high sensitivity should be used. These include acute toxicity testing, Irwing's screen (27), the functional observational battery (FOB) (26), and the motor activity test (MAT) (28), or, even better, behavioral test batteries $(16,29)$. Once a chemical has been identified as neurotoxic, the next objective is to determine dose-effect relationships more precisely. An important objective for standard setting is to determine the no-observed effect levels (NOEL). This task often requires sophisticated and sensitive techniques, as well as many experimental observations $(23,30,31)$.

Compounds that are structurally related to other chemicals with a well known neurotoxic effect, such as peripheral neuropathy, could be tested using a method suitable for determining this specific effect (eg, nerve conduction velocity measurements). For example, 1,2-diethyl benzene is structurally related to $n$-hexane, and electrophysiological examinations confirm that the metabolite of 1,2-diethyl benzene 
induces axonal degeneration, as does 2,5-hexanedione (32).

Compounds belonging to groups of chemicals with a well-known mechanism of neurotoxic action can sometimes be tested with specific in vitro test methods. For example, the NTE assay has been evolved as a rapid and sensitive screening test for detecting the neurotoxic potential of organophosphates (22).

So far, an "Ames test" for neurotoxicity has not been developed and, except for special cases, as with the NTE assay, in vitro test methods are still not suitable for sensitive testing for the neurotoxicity of chemicals (33). However, promising results have been reported recently by Stoltenburg-Didinger et al (34). They found specific neurotoxic effects of different organic solvents on dissociated cultures of nerve cells. These methods may be of increasing significance in the future. However, for the time being, data from in vitro tests and QSAR analyses should only be used as support for data from animal and human studies.

Well-performed epidemiologic studies may be the most valuable source of data on human neurotoxicity. Nevertheless, there are many limitations and weaknesses in the existing studies. These limitations and weaknesses include a lack of compensation for the "healthy worker effect" in cross-sectional studies, inability to exclude reversible effects of exposure, doubtful exposure assessment, and lack of sensitivity and comparability of the methods used for assessing nervous system function. With this background, a core protocol has been prepared by experts to promote an international collaborative epidemiologic study on the possible effect that may result from long-term exposure to organic solvents (18). The guidelines in this report can be used for other epidemiologic studies as well. In the future, epidemiologic studies can provide answers to the more complex questions concerning human neurotoxicity, but human data from case reports, industrial accidents, and environmental poisonings will still provide important information with which to evaluate chemicals for neurotoxicity.

\section{Evaluation of evidence for neurotoxicity}

As in all fields of toxicology there is information on biological effects on various types of organisms, ranging from cells (or even molecules) to different species of animals to humans and human populations. However, in dealing with human neurotoxicology in general and occupational neurotoxicology in particular, it is evident that the end point in the evaluation is neurotoxicity to humans. Consequently, data from human studies are the most important, but, as previously discussed, animal data must also be used.

Based on the definition of neurotoxicity and the criteria described in the preceding section, a model for evaluating existing data on neurotoxicity has been developed. The proposed model for evaluating experimental data, as well as the terminology used, has many similarities with the model that the International Agency for Research on Cancer has developed for evaluating carcinogenicity data (35). The evaluation process involves four steps, as indicated by the Roman numerals in figure 1 . The first step (I) concerns the evaluation of evidence reported for neurotoxicity in each single study on animals and humans. The second step (II) concerns the evaluation of all animal data and all human data and results in a statement about the overall degree of evidence for neurotoxicity in animals and humans. In the third step (III), the evidence for neurotoxicity in animals and humans is combined in a statement regarding neurotoxicity to humans. Finally, in step IV, the neurotoxic potency of the chemical classified as neurotoxic is described in terms of the dose-effect relationship as far as data are available. The individual steps in the evaluation process are described in more detail in the following.

\section{Degree of evidence presented by single studies}

In evaluating reports on neurotoxicity, the following aspects should be taken into account: type of study, sensitivity, specificity, effect level demonstrated, species used, gender and age, strength of causality (presence or absence of confounding factors), number of observations, statistics, and the like. However, first of all, the objective of the study should be clear.

The following three main objectives in neurotoxicity studies can be described: (i) detection of whether the structure or function of the nervous system is altered by the chemical, (ii) description of the nature of the alteration associated with exposure, and (iii) determination of dose- and time-effect relationships aimed at establishing a NOEL.

As there are many different methods for determining the neurotoxic effects of a chemical, it is important first to evaluate whether the experimental design and the methods used are appropriate for the objectives of the study and for the conclusions drawn. In other words, the validity of the study should be analyzed (19). A discussion of the pros and cons of the numerous methods used in neurotoxicity testing can be found in the literature $(6,24,26,36-39)$. Second, it is important to consider how precisely the compound under study is defined. Could the observed effect be due to impurities in the chemical used, or, in the case of epidemiologic studies, have the individuals been exposed to several different chemicals at the same time (40)? Third, the dose has to be evaluated. Is it reasonably below the lethal dose, how was it monitored, and is the nervous system the primary target of the chemical? In inhalation studies and especially in epidemiologic studies, the dose estimation may be difficult and inaccurate $(18,40)$. Finally, the consistency of the results should 

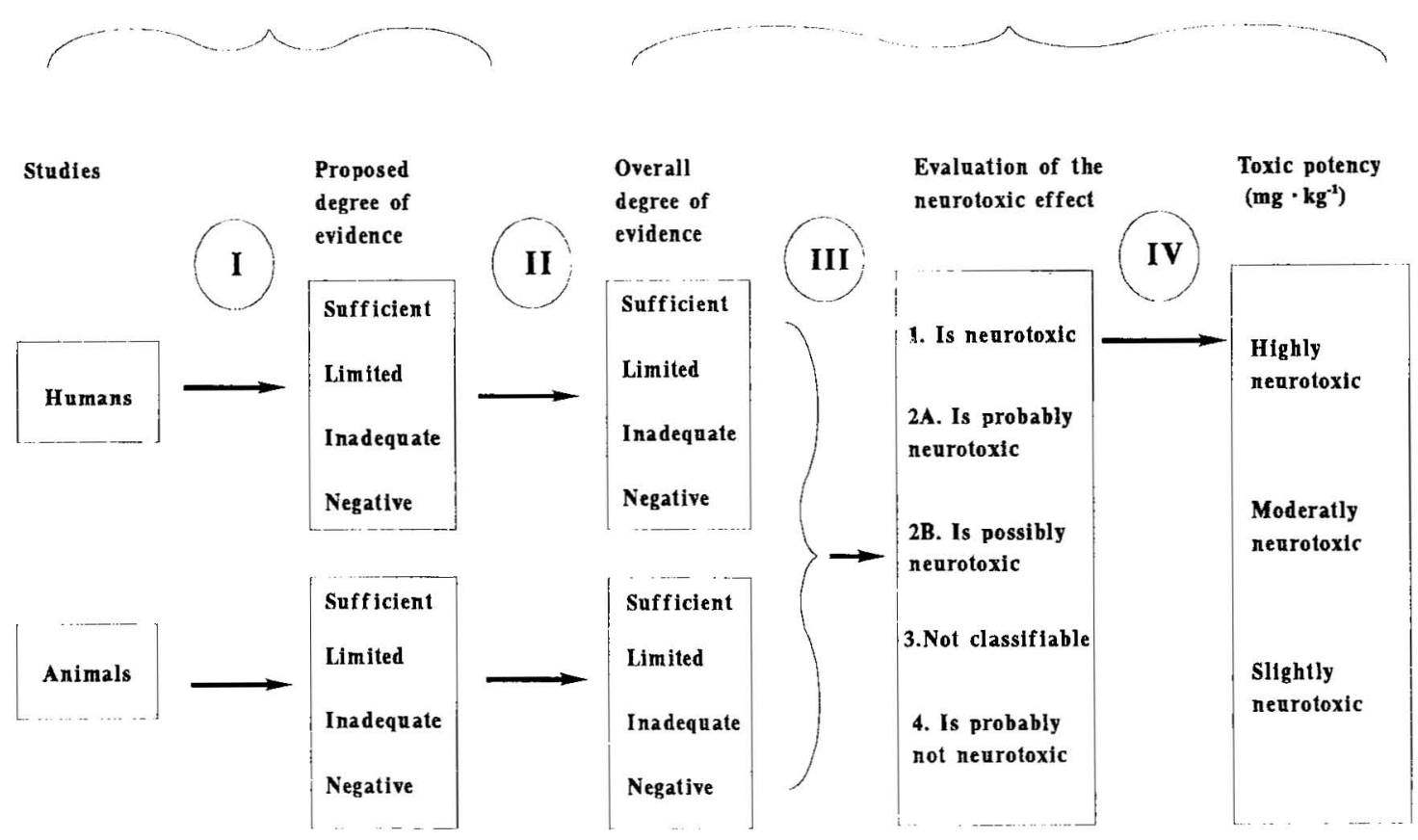

Figure 1. Evaluation of neurotoxicity data. $(I=$ evaluation of degree of evidence from single studies, $I I=$ evaluation of all animal and all human data, III = evaluation combining animal and human data, and IV = evaluation of neurotoxic potency)

be evaluated through a determination of the number of observations and the statistics used $(30,38,39)$.

This evaluation step, which concerns the quality and the credibility of an investigation, results in a statement on the degree of evidence for neurotoxicity presented by that single study.

The following four different levels of evidence are proposed: (i) sufficient evidence, which is achieved by well-performed, high-quality studies describing effects on level 4, 5, or 6 in table 1; (ii) limited evidence, which is achieved by well-performed studies demonstrating effects on level 1, 2 or 3 or less wellperformed studies showing effects on level 4,5 or 6; (iii) inadequate evidence, which is achieved from studies of no value, either because they are of poor quality or only have marginal relevance to the field of neurotoxicity; poor-quality studies demonstrating effects on the low level 1, 2 or 3 may also represent inadequate evidence; (iv) negative evidence is obtained from well-performed studies showing no neurotoxic effects using methods designed for any lev$\mathrm{el}$ in table 1 . The last class represents a continuum of studies ranging from those of no value to those demonstrating with reasonable certainty that a chemical is not neurotoxic. However, from a scientific point of view, negative evidence is always more dubious in nature than a positive result. Even with a reliable study presenting negative evidence, the possibility cannot be excluded that, with another method, dose, duration of exposure, species, or route of administration, neurotoxicity might be demonstrated. Thus negative evidence is only tentative, whereas adequate positive evidence is definitive.

\section{Evaluation of all animal data and all human data}

In the second step of the evaluation process the evidence is classified for all animal and human studies.

Animal data. Compared with humans, animals have different patterns of metabolism, and different species often show different sensitivity to drugs and toxic compounds. Sufficient evidence for the neurotoxicity of a chemical in animals can therefore generally be obtained only if at least one well-performed experiment shows similar effects in two or more species. However, in some cases, two or more independently performed experiments on one species or one study supported by evidence from in vitro tests or QSAR analysis may be sufficient. For example, sufficient evidence from only one species may be satisfactory for claiming the neurotoxicity of 1,2-diethyl benzene and its metabolite because of their structural relationship to $n$-hexane and its metabolite, which is known to induce human neurotoxicity (32). In other words, if a chemical is found to be neurotoxic in one species, it can only be evaluated as neurotoxic to oth- 
er species if strong supporting evidence from in vitro tests or QSAR analyses exist.

Human data. In contrast to the requirements for animal experiments, only one well-performed human study showing effects on level 4,5 , or 6 (table 1 ) is required for sufficient evidence of neurotoxicity to humans. For ethical reasons, controlled experiments fulfilling these requirements are generally not available, and, therefore, epidemiologic studies and case reports are the main source of human data.

In general, several studies, each representing limited or inadequate evidence, can never increase the overall degree of evidence to a higher level than that of the highest rating individual study. In some situations, when the same mechanism is examined, however, several reports with limited evidence can add up to sufficient evidence.

Studies suggesting negative evidence of neurotoxicity may throw doubt on similar studies which indicate that the same chemical is neurotoxic, and the evaluation may result in classifying the available evidence as inadequate. Nevertheless, a single negative study is only of limited value, but, if there are several well-performed studies showing no neurotoxicity, the overall evidence may be classified as negative. In principle, however, a chemical can never be proved not neurotoxic, and therefore the evidence for a lack of neurotoxicity should be substantial before it is classified as negative.

\section{Combining animal and human data}

In the final part of the evaluation, the overall degrees of evidence for neurotoxicity in animals and humans are combined in a statement regarding the certainty with which the chemical in question is considered neurotoxic to humans. The outcome of all different combinations of evidence of neurotoxicity in animals and humans is shown in table 2 . The result is five groups depending on the degree of evidence for neurotoxicity. [The group designation corresponds to that used by the International Agency for Research on Cancer (IARC) in its classification of chemical carcinogens].

Group 1. Neurotoxic to humans. Agents in group 1 are those with sufficient evidence from human studies or limited evidence from humans supported by sufficient evidence from animal experiments. If there is sufficient evidence for neurotoxicity in humans, the chemical is, of course, neurotoxic to humans. However, extrapolation from animal experiments to conditions that prevail in industrial exposure is difficult. If a chemical has been proved neurotoxic in animal experiments, it does not necessarily imply that the same chemical is harmful to occupationally exposed humans. In recognition of the fact that a toxic effect may be specific only to some species, neurotoxicity to animals can at best only suggest with a certain degree of probability that the chemical is also neurotoxic in humans. However, the probability of neurotoxicity to humans increases if the effect has been demonstrated in closely related species (primates), or in species that are physiologically similar to man, and if supporting evidence from in vitro tests or QSAR analyses exists. We therefore suggest that a chemical agent be classified as neurotoxic to humans on the basis of sufficient evidence from animal experiments and limited evidence from human studies.

Group 2A. Probably neurotoxic to humans. Chemicals classified into group $2 \mathrm{~A}$ are those with limited evidence from human and animal studies or sufficient evidence from animal studies alone or in combination with inadequate evidence from human studies or supporting evidence from in vitro tests or QSAR analyses.

Table 2. Classification of the neurotoxicity of a chemical agent to humans on the basis of the degree of evidence from animal and human studies. Group designation (group 1, 2A, 2B, 3, and 4) corresponds to that used by the International Agency for Research on Cancer for chemical carcinogens.

\begin{tabular}{lllll}
\hline $\begin{array}{l}\text { Degree of } \\
\text { evidence from } \\
\text { animal studies }\end{array}$ & \multicolumn{4}{c}{ Degree of evidence from human studies } \\
\cline { 2 - 5 } Sufficient & Sufficient & Limited & Inadequate & Negative \\
& $\begin{array}{l}\text { Group 1, } \\
\text { neurotoxic }\end{array}$ & $\begin{array}{l}\text { Group 1, } \\
\text { neurotoxic }\end{array}$ & $\begin{array}{l}\text { Group 2A, } \\
\text { probably neuro- } \\
\text { toxic }\end{array}$ & $\begin{array}{l}\text { Group 2B, } \\
\text { possibly neuro- } \\
\text { toxic }\end{array}$ \\
Limited & $\begin{array}{l}\text { Group 1, } \\
\text { neurotoxic }\end{array}$ & $\begin{array}{l}\text { Group 2A, } \\
\text { probably neuro- } \\
\text { toxic }\end{array}$ & $\begin{array}{l}\text { Group 2B, } \\
\text { possibly neuro- } \\
\text { toxic }\end{array}$ & $\begin{array}{l}\text { Group 3, } \\
\text { not classifiable }\end{array}$ \\
Inadequate & $\begin{array}{l}\text { Group 1, } \\
\text { neurotoxic }\end{array}$ & $\begin{array}{l}\text { Gossibly neuro- } \\
\text { toxic }\end{array}$ & not classifiable & $\begin{array}{l}\text { Group 4, } \\
\text { probably not } \\
\text { neurotoxic }\end{array}$ \\
Negative & $\begin{array}{l}\text { Group 2B, } \\
\text { possibly neuro- }\end{array}$ & Group 3, & Got classifiable & $\begin{array}{l}\text { Group 4, } \\
\text { probably not } \\
\text { neurotoxic }\end{array}$ \\
\hline
\end{tabular}


Group 2B. Possibly neurotoxic to humans. Chemicals in group $2 \mathrm{~B}$ are those for which the evidence from human studies is limited to negative and the evidence from animal studies is sufficient to negative. (See table 2.)

Group 3. Cannot be classified. The available data on chemicals in group 3 are inadequate or contradicting.

Group 4. Probably not neurotoxic to humans. Chemicals for which there is negative evidence for neurotoxicity in humans and negative or inadequate evidence from animal studies belong to group 4 .

\section{Evaluation of neurotoxic potency}

It would lead too far to provide full documentation on how to establish the potency of a neurotoxic chemical. The following general considerations should, however, be made. An evaluation of the neurotoxic potency of a chemical is based upon a description of the dose-effect relationships observed in one or more studies. In theory, it is possible to describe the relationship between exposure and effect from experiments examining the toxic effect of two or more doses. The position and slope of the doseeffect curve provides an estimate of the potency of the chemical. However, before the most reliable and precise index of potency can be achieved, dose-effect relationships should ideally be based on all available observations.

Once a functional relationship between dose and effect has been established, it is generally possible to predict the NOEL and the lowest-observed effect level (LOEL), which can also be used as a measure of toxic potential. The NOEL, although often less informative than the LOEL, can then be used to set exposure limits below which workers (or the public) can be exposed without adverse health effects.

Dose-effect relationships and potency are usually first determined more precisely when the target organ or mechanism of toxic action has been established. It is therefore only relevant to discuss potency for chemicals that have been proved neurotoxic (chemicals in group 1). The measures used as indices of the toxic effect must be expressed in a manner that can be directly quantified (41). In combining data from different studies, it is also important that the duration of the exposures and routes of administration be taken into consideration.

It is often necessary to use toxicokinetic models to compare different studies in which different exposure routes and exposure patterns have been used (42). Toxicokinetic models make it possible, at least theoretically, to calculate the concentration (mg . $\mathrm{kg}^{-1}$ ) in the blood stream or at the target site as a function of time, provided certain kinetic data for the substance and its metabolism are known and relevant physiological parameters for the species used are available $(43,44)$. The use of physiologically based pharmacokinetics models has also been suggested for interspecies extrapolations (45).

The route of administration and the duration of exposure are of significance for the resulting effect. For occupational regulation, experiments using administration by inhalation or by skin contact have the highest informative value. The administration of chemicals by other routes may give rise to transient concentration levels and effects that are of no relevance to occupational exposure. Experiments using different exposure routes and exposure durations can, at least to some extent, be compared through calculations of the absorbed dose and peak concentrations according to toxicokinetic models. It has been suggested that the absorbed dose should be given in $\mathrm{mg} \cdot \mathrm{kg}^{-1} \cdot \mathrm{d}^{-1}$, and, if possible, the peak concentrations at the target site or in the blood should be estimated to allow comparison with the values relevant for occupational exposure.

We suggest that the values listed in table 3 be used for classifying neurotoxic chemicals according to their potency.

Classifying and ranking neurotoxic chemicals according to their potency may be of importance for regulatory purposes. Furthermore, ranking may be a valuable tool for risk assessment and for the industrial hygienist in considering potential candidates as substitutes for hazardous compounds. However, any classification is arbitrary in nature, and the regulatory consequences that it may entail depend solely on political decisions. Furthermore, the potency of a chemical should not be confused with the risk of being exposed to the compound. Some chemicals may be classified as highly potent, but they do not necessarily present a serious risk to the work environment. For example, aluminum is highly neurotoxic when in contact with neurons, but aluminum is unlikely to be absorbed during work with aluminum compounds. Finally, it is relevant to mention that potencies should only be compared within a class of related chemicals.

The values in table 3 have been used for classifying the five neurotoxic chemicals in table 4 according to their potency in the work environment.

Table 3. Suggested classification of neurotoxic chemicals according to potency.

\begin{tabular}{lcc}
\hline Potency & Dose $^{\mathrm{a}}$ & \\
\hline Slightly neurotoxic & $200-2000$ & $\mathrm{mg} \cdot \mathrm{kg}^{-1} \cdot \mathrm{d}^{-1}$ \\
Moderately neurotoxic & $20-200$ & $\mathrm{mg} \cdot \mathrm{kg}^{-1} \cdot \mathrm{d}^{-1}$ \\
Highly neurotoxic & $<20$ & $\mathrm{mg} \cdot \mathrm{kg}^{-1} \cdot \mathrm{d}^{-1}$ \\
\hline
\end{tabular}

a Absorbed dose per day required to elict a consistent effect on one or more of the levels 4 to 6 in table 1 . 
Table 4. Summary of the evaluation process for the 10 chemicals evaluated.

\begin{tabular}{|c|c|c|c|c|}
\hline \multirow{2}{*}{ Chemical } & \multicolumn{2}{|c|}{ Degree of evidence } & \multirow{2}{*}{ Conclusion } & \multirow{2}{*}{ Potency ${ }^{a}$} \\
\hline & Animals & Humans & & \\
\hline Aluminum & Sufficient & Limited & Neurotoxic & Highb $^{b}$ \\
\hline Cyclohexanone & Inadequate & Inadequate & Not classifiable & . \\
\hline Dichlorvos & Limited & Inadequate & $\begin{array}{l}\text { Possibly } \\
\text { neurotoxic }\end{array}$ & $\cdot$ \\
\hline Formaldehyde & No data & Inadequate & Not classifiable & $\cdot$ \\
\hline Manganese & Sufficient & Sufficient & Neurotoxic & High \\
\hline$n$-Hexane & Sufficient & Limited & Neurotoxic & $\begin{array}{l}\text { Moderate - } \\
\text { high }\end{array}$ \\
\hline Tetrahydrofuran & Limited & Inadequate & $\begin{array}{l}\text { Possibly } \\
\text { neurotoxic }\end{array}$ & $\cdot$ \\
\hline Trichlorethylene & Sufficient & Limited & Neurotoxic & Moderate \\
\hline $\begin{array}{l}\text { Tri-ortho-cresyl } \\
\text { phosphate }\end{array}$ & Sufficient & Sufficient & Neurotoxic & High \\
\hline Vinyl chloride & No data & Limited & $\begin{array}{l}\text { Possibly } \\
\text { neurotoxic }\end{array}$ & $\cdot$ \\
\hline
\end{tabular}

a The potency (slightly, moderately, or highly neurotoxic) of the chemical at the target site has only been established for those chemicals that are neurotoxic.

b Aluminum is generally considered a nontoxic compound due to its low uptake by inhalation and ingestion, but when it has reached the target site, the neurotoxic potency of aluminum is fairly high.

\section{Testing of the model}

For the purpose of testing how the model works, selected literature on 10 chemicals was evaluated according to the criteria described in the preceding sections. The 10 chemicals were aluminum, cyclohexanone, dichlorvos, formaldehyde, manganese, $n$-hexane, tetrahydrofuran, trichloroethylene, tri-orthocresyl phosphate, and vinyl chloride. The studies on which the evaluation was based are listed in appendix 1 , and a fully documented report (46) is available upon request. ${ }^{5}$

The results of the evaluation are summarized in table 4. Aluminum, manganese, $n$-hexane, trichlorethylene, and tri-ortho-cresyl phosphate all were found to be neurotoxic to humans (group 1), while dichlorvos, tetrahydrofuran, and vinyl chloride were considered possibly neurotoxic (group 2B). Cyclohexanone and formaldehyde were not classifiable according to the present model (ie, there was no evidence for neurotoxicity nor was there evidence which suggested that they are not neurotoxic). The classification reflects the results of a hazard assessment, but not the risk associated with working with the chemicals. In the case of aluminum the evaluation led to a classification of neurotoxic to humans, and highly potent, but the risk of being poisoned by aluminum during normal work is considered fairly low, as aluminum is practically not absorbed by inhalation or ingestion.

\footnotetext{
5 Address requests to Dr L Simonsen, National Institute of Occupational Health, Lersø Parkallé 105, DK-2100 Copenhagen, Denmark.
}

\section{Discussion}

According to our knowledge this is the first attempt to provide an operational model for evaluating information on the neurotoxicity of chemicals. Although the model seems to serve its purpose, we are aware that it is not free of pitfalls. Any classification of continuous functions will give rise to borderline problems - in this case the most evident in table 2. There is no strict line between any of the four degrees of evidence, neither for animal nor for human data. Furthermore, neurotoxicity has many different facets, and neurotoxic chemicals can interfere with the nervous system at many different sites and therefore give rise to many different effects and symptoms. Hence toxic responses of the nervous system to chemicals can be detected in many ways, and assessing neurotoxicity is therefore a process involving subjective evaluation of the methods used, the way the experiment was performed, and the interpretations made. These processes can hardly be set up in a prescription and will therefore always give rise to some discrepancy when performed by different persons. Therefore, although the model appears rather "mechanistic," it is definitely not free from subjective judgment.

The model bears many similarities to the IARC model for classifying carcinogenic chemicals, and these similarities are fully intentional (35), partly due to the similarity of the nature of the task. On the other hand, it is clear that the models differ in detail. A major obstacle for developing a model or setting up criteria for neurotoxicity is, unlike for carcinogenicity, that the toxic response is not all or none; instead it represents a continuum in severity. Consequently, 
a model for neurotoxicity will necessarily be more elaborate than the IARC model. Furthermore, it has to be established at which response or symptom level an effect has to be considered adverse, which is again unlike cancer, for which any event in the process of developing a tumor is not only undesirable but may also turn out to be fatal.

Nevertheless, it has been possible to classify the neurotoxic chemicals into five groups comparable to the grouping used by the IARC model. This classification has been used to make the interpretation of the model easier.

During testing of the model we often found it particularly difficult to evaluate whether the observed effects were directly related to the exposure conditions. Furthermore, it often appeared that the information in many reports was insufficient for establishing dose-response relationships.

Another problem was how to handle information dealing with effects seen in lower animals, isolated cells, and cell cultures. The working group was mostly inclined to consider the use of cell cultures or in vitro experiments for the screening of neurotoxicants as premature. However, these methods may be valuable for examining neurotoxic mechanisms. The use of data from in vitro tests and QSAR analyses is consequently suggested to be limited to supporting the evidence from human and animal studies.

In spite of these reservations, we feel that the model works reasonably well for evaluating the strength of the scientific evidence with respect to the neurotoxicity of a chemical.

\section{Acknowledgments}

This work was supported by the Nordic Council of Ministers. We are grateful to our colleagues who provided valuable comments.

\section{References}

1. Spencer PS, Schaumburg HH, ed. Experimental and clinical neurotoxicology. Baltimore, MD: Williams \& Wilkins Company, 1980.

2. O'Donoghue JL, ed. Neurotoxicity of industrial and commercial chemicals; vol I \& II. Boca Raton, FL: CRC Press Inc, 1985.

3. Kandel ER, Schwartz JH, Jessell TM, ed. Principles of neural science. New York, NY: Elsevier, 1991.

4. Small SA, Kandel ER, Hawkins RD. Activity-dependent enhancement of presynaptic inhibition in aplysia sensory neurons. Science 1989;243:1603-15.

5. Damstra T. Environmental chemical and nervous system dysfunction. Yale J Biol Med 1978;51:457—68.

6. World Health Organization (WHO). Principles and methods for the assessment of neurotoxicity associated with exposure to chemicals. Geneva: WHO, 1986. (Environmental health criteria; no 60.)

7. Anger WK. Neurobehavioral testing of chemicals: impact on recommended standards. Neurobehav Toxicol Teratology 1984;6:147-53.

8. Reiter LW. Neurotoxicology in regulation and risk assessment. Dev Pharmacol Ther 1987; 10:354-68.

9. Kahle W, Leonhard H, Platzer W, ed. Color atlas and textbook of human anatomy; vol 3 (Nervous system and sensory organs). Stuttgart: Georg Thime Verlag, 1986.

10. Jacobs JM. Vascular permeability and neurotoxicity. Environ Health Perspect 1978;26:107-16.

11. Anger WK ,Johnson BL. Chemicals affecting behavior. In: O'Donoghue JL, ed. Neurotoxicity of industrial and commercial chemicals. Boca Raton, FL: CRC Press, 1985.

12. Weiss B. Behavioral toxicology and environmental health science: opportunity and challenge for psychology. Am Psychol 1983;1174-87.

13. Weiss B, Laties VG. Assays for behavioral toxicity: a strategy for the environmental protection agency. Neurobehav Toxicol 1979;1 suppl 1:213-5.

14. World Health Organization (WHO). Principles and methods of evaluating the toxicity of chemicals: parts 1 and 2. Geneva: WHO, 1978. (Environmental health criteria; no 6, parts 1 and 2.)

15. National Institute for Occupational Safety and Health (NIOSH). Organic solvent neurotoxicity. Atlanta, Ga: NIOSH, 1987. (Central intellegence bulletin; no 48.) (DHHS (US NIOSH) publication; no 87-104.)

16. Organization for Economic Cooperation and Development (OECD). 1990 OECD ad hoc meeting on neurotoxicity testing, summary report. Washington, DC: United States Environmental Protection Agency, 1990.

17. Wurtman RJ, Maher TJ. Strategies for assessing the effects of food additives on the brain and behavior. Fund Appl Toxicol 1984;4:318-22.

18. World Health Organization (WHO). Solvents and the central nervous system - core protocol. Copenhagen: WHO, 1989. (Environmental health criteria; no 36.)

19. Sette WF. Complexity of neurotoxicological assessment. Neurotoxicol Teratology 1987;9:411-6.

20. Spencer PS, Schaumburg HH. An expanded classification of neurotoxic responses based on cellular targets of chemical agents. Acta Neurol Scand 1984;70 suppl 100:9-19.

21. Snyder SH, D’Amato RJ. MPTP: a neurotoxic relevant to the pathophysiology of Parkinson's disease. Neurotoxicology 1986;36:250-8.

22. Davis CS, Johnson MK, Richardson RJ. Organophosphorus compounds. In: O'Donoghue JL, ed. Neurotoxicity of industrial and commercial chemicals. Boca Raton, FL: CRC Press, 1985:1-23.

23. Dewar AJ. Neurotoxicity. In: Balls M, Riddell RJ, Worden AN, ed. Animals and alternatives in toxicity testing, London New York: Academic Press, 1983: 229-98.

24. Buckholtz NS, Panem S. Regulation and evolving science: neurobehavioral toxicology. Neurobehav Toxicol Teratology 1986;8:89—96.

25. Tilson HA. Behavioral indices of neurotoxicity. Toxicol Pathol 1990;18(1 part 2):96- 4 .

26. Mattsson JL, Eisenbrandt DL, Albee RR. Screening for neurotoxicity: complementarity of functional and morphologic techniques. Toxicol Pathol 1990;18(1) part 2:115-27.

27. Irwin S. Comprehensive observational assessment: Ia. a systematic, quantitative procedure for assessing the behavioral and psychologic sate of the mouse. Psychopharmacologia 1968;13:222-57.

28. MacPhail RC, Peele DB, Crofton KM. Motor activity and screening for neurotoxicity. J Am Coll Toxicol 1989;8(1): $117-24$.

29. Pryor GT, Uyeno ET, Tilson HA, Mitchell CL. Assessment of chemicals using a battery of neurobehavioral tests: a comparative study. Neurobehav Toxicol Teratology 1983;5:91-117.

30. Dews PB. Epistemology of screening for behavioral toxicity. In: Mitchell CL, ed. Nervous system toxicology. New York, NY: Raven Press, 1982:229-36.

31. McMillan D. Risk assessment for neurobehavioral tox- 
icity. Environ Health Perspect 1987;76:155-61.

32. Gagnaire F, Marinac B, De Ceaurriz J. Diethyl-benzene-induced sensorimotor neuropathy in rats. J Appl Toxicol 1990;10(2):105-12.

33. Walum $\mathrm{E}$, Hansson $\mathrm{E}$, Harvey AL. In vitro testing of neurotoxicity. Alternatives Lab Anim 1990;18:15379.

34. Stoltenburg-Didinger G, Boegner F, Griining W, Wagner M, Marx P, Altenkirch H. Specific neurotoxic effects of different organic solvents on dissociated cultures of the nervous system. In: Mutti A, Costa LG, Manzo L, Cranmer JM, ed. Current issues in neurotoxicology. Little Rock, AR: Intox Press Inc, 1992: $161-4$.

35. International Agency for Research on Cancer (IARC). IARC overall evaluation of carcinogenicity: an updating of IARC monographs volumes 1 to 42 . Lyon: IARC, 1987. (IARC monographs on the evaluation of carcinogenic risks to humans; suppl 7.)

36. Tilson HA, Mitchell CL, Cabe PA. Screening for neurobehavioral toxicity: the need for and examples of validation of testing procedures. Neurobehav Toxicol 1979;1 suppl 1:137-48.

37. Broxup B, Robinson K, Losos G, Beyrouty P. Correlation between behavioral and pathological changes in the evaluation of neurotoxicity. Toxicol Appl Pharmacol 1990;101:510-20.

38. Gad SC. Principles of screening in toxicology with special emphasis on applications to neurotoxicology. J Am Coll Toxicol 1989;8(1):21 -7.
39. Gad SC. Screens in neurotoxicity: objectives, design, and analysis, with the functional observational battery as a case example. J Am Coll Toxicol 1989;8(2):287301 .

40. Olsen E, Christensen JM, Simonsen L, ed. Assessment of exposure to organic solvents. Copenhagen: WHO, 1993.

41. Klaassen CD. Absorption, distribution and excretion of toxicants. In: Klaassen CD, Amdur MO, Doull J, ed. Toxicology: the basic science of poisons. New York, NY: MacMillan, 1986:33-64.

42. Watanabe PG, Schumann AM, Reitz RH. Toxicokinetics in the evaluation of toxicity data. Regul Toxicol Pharmacol 1988;8:408-13.

43. Andersen ME, Clewell HJ, Gargas ML, Smith FA, Reitz RH. Physiologically based pharmacokinetics and the risk assessment process for methylene chloride. Toxicol Appl Pharmacol 1987;87:185-205.

44. Conolly RB. Biologically-based models for toxic effects: tools for hypothesis testing and improving health risk assessments. CIIT Act 1990;10(5): $1-8$.

45. Reitz RH, McDougal JN, Himmelstein MW, Nolan RJ, Schumann AM. Physiologically based pharmacokinetic modeling with methylchloroform: implications for interspecies, high/low dose, and dose route extrapolations. Toxicol Appl Pharmacol 1988;95:185-99.

46. Johnsen $\mathrm{H}$, Lund S P, Matikainen E, Midtgård U, Simonsen L, Wennberg A, ed. Occupational neurotoxicity: criteria document for evaluation of existing data. Copenhagen: Nordic Council of Ministers, 1992.

\section{Appendix 1}

\section{Literature on which the evaluations have been based}

\section{Aluminum}

1. Altmann P, Dhanesha U, Hamon C, Cunningham J, Blair J, Marsh F. Disturbance on cerebral function by aluminum in haemodialysis patients without overt aluminum toxicity. Lancet 1989;1:7-12.

2. Garrett PJ, Mulcahy D, Carmody M, O'Dwyer WF. Aluminum encephalopathy: clinical and immunological features. Q J Med 1988;69:775-83.

3. Kowall NW, Pendlebury WW, Kessler JB, Perl DP, Beal MF. Aluminum-induced neurofibrillary degeneration affects a subset of neurons in rabbit cerebral cortex, basal forebrain and upper brain stem. Neuroscience 1989;29:329-37.

4. Lipman JJ, Colowick SP, Lawrence PL, Abumrad NN. Aluminum induced encephalopathy in the rat. Life Sci $1988 ; 42: 863-75$.

5. Sprague SM, Corwin HL, Tanner CM, Wilson RS, Green BJ, Goetz CG. Relationship of aluminum to neurocognitive dysfunction in chronic dialysis patients. Arch Intern Med 1988; 148:2169-72.

\section{Cyclohexanone}

1. De Ceaurriz J, Desiles JP, Marignac B, Muller J, Guenier JP, Bonnet P. Concentration-dependent behavioral changes in mice following short-term inhalation exposure to various industrial solvents. Toxicol Appl Pharmacol 1983;67:383-9.

2. Greener Y, Gillies B, Wienckowski D, Schmidt D, Woods E, Youkilis E. Assessment of the safety of chemicals administered intravenously in the neonatal rat. Teratology 1987;35:187-94.
3. Greener Y, Martis L, Indacochea-Redmond N. Assessment of the toxicity of cyclohexanone administered intravenously to Wistar and Gunn rats. J Toxicol Environ Health 1982;10:385-96.

4. Gupta PK, Lawrence WH, Turner JE, Autian J. Toxicological aspects of cyclohexanone. Toxicol Appl Pharmacol 1979;49:525-33.

5. Koeferl MT, Miller TR, Martis L, Fisher JD, Garvin PJ, Dorner JL. Influence of concentration and rate of intravenous administration of the toxicity of cyclohexanone in beagle dogs. Toxicol Appl Pharmacol 1981; 59:215-29.

6. Perbellini L, De Gandis D, Semenzato F, Bongiovanni LG. Studio sperimentale neurotossicata del cicloeasanolo e del cicloesanone. Med Lav 1981;2:102-7.

7. Sakata M, Kikuchi J, Haga M. Disposition of acetone, methyl ethyl ketone and cyclohexanone in acute poisoning. Clin Toxicol 1989;27:67-77.

\section{Dichlorvos}

1. Caroldi S, Lotti M. Delayed neurotoxicity caused by a single massive dose of Dichlorvos to adult hens. Toxicol Lett 1981;9:157-9.

2. Desi I, Nagymajtenyi L. Neurotoxicologic investigations of the pesticide Dichlorvos (DDVP). Toxicology $1988 ; 49: 141-8$.

3. Johnson MK. The anomalous behaviour of dimethyl phosphates in the biochemical test for delayed neurotoxicity. Arch Toxicol 1978;41:107-10.

4. Vailescu C, Florescu A. Clinical and electrophysiological study of neuropathy after organophosphorus compounds poisoning. Arch Toxicol 1980;43:305-15. 


\section{Formaldehyde}

1. Andersen I, Mølhave L. Controlled human studies with formaldehyde. In: Gibson JE, ed. Formaldehyde toxicity. Washington DC: Hemisphere Publishing Corp, 1983:154-65.

2. Bach B, Mølhave L, Pedersen OF. Human reactions during controlled exposures to low concentrations of formaldehyde - performance tests. Indoor Air 1987:620-4.

3. Bort G, Heydt G. A case of toxic personality change and reduced performance after formaldehyde exposure. Zentralbl Arbeitsmed Arbeitsch Prophl Erogonomie 1987;37:206-12.

4. Kilbourn KH, Seidman BC, Warshaw R. Neurobehavioural and respiratory symptoms of formaldehyde and xylene exposure in histology technicians. Arch Environ Health 1985;40:229-33.

5. Kilburn KH, Warshaw R, Thornton JC. Formaldehyde impairs memory, equilibrium, and dexterity in histology technicians: effects which persist for days after exposure. Arch Environ Health 1987;42:117-20.

6. Kilburn KH, Warshaw R, Thornton JC, Husmark I. An examination of factors that could affect choice reaction time in histology technicians. Am J Ind Med 1989;15:679-86.

\section{Manganese}

1. Chandra SV. Psychiatric illness due to manganese poisoning. Act Psychiatry Scand 1983;67 suppl 303:4954.

2. Chandra SV, Shukla GS. Manganese encephalopathy in growing rats. Environ Res 1978;15:28-37.

3. Chandra SV, Shukla GS, Shrivastava RS. An explanatory study of manganese exposure to welders. Clin Toxicol 1981;18(4):407-16.

4. Duflou H, Maenhaut De RJ. Regional distribution of potassium, calcium and six trace elements in normal human brain. Neurochem Res 1989;14:1099-112.

5. Roels H, Lauwerys R, Buchets J-P, Genet P, Sarhan MJ, Hanotiau I, et al. Epidemiological survey among workers exposed to manganese: effects on lung, central nervous system and some biological indices. Am $\mathrm{J}$ Ind Med 1987;11:301-27.

6. Seeber A, Dotzauer H, Schneider H. Psychodiagnostik bei Blei-, Quecksilber- und Manganexposition ein Ehrfahrungsbereicht. Z Gesamte Hyg 1984;30: 702-6.

7. Shukla GS, Chandra SV. Striatal turnover and L-dopa treatment after short term exposure of rats to manganese. Arch Toxicol 1981;47:191-6.

8. Shukla GS, Chandra SV, Seth PK. Effects of manganese on the levels of DNA, RNA, DNase and RNase in cerebrum, cerebellum and rest of brain regions in rat. Act Pharmacol Toxicol 1981;39:562-9.

9. Wennberg A, Iregren A, Struwe G, Cizinsky G, Hagman M, Johansson L. Manganese exposure in steel smelteries a health hazard to the nervous system. Scand J Work Environ Health 1991;17(4):255-62.

\section{n-Hexane}

1. Aiello I, Rosati G, Serra G, Manca M. Subclinical neuropathic disorders and precautionary measures in the shoe industry - an electrophysiological investigation. Acta Neurol (Napoli) 1980;35:285-92.

2. Iida M. Neurophysiological studies of $n$-hexane polyneuropathy in the sandal factory. Electroenceph Clin Neurophysiol 1982;36 suppl:671-81.

3. Mutti A, Ferri F, Lommi G, Lotta S, Lucertini S, Franchini I. n-Hexane-induced changes in nerve conduction velocities and somatosensory evoked potentials. Int Arch Occup Environ Health 1982;51:45-54.
4. Ono $\mathrm{Y}$, Takeuchi $\mathrm{Y}$, Hisanaga N, Iwata $\mathrm{M}$, Kitoh J, Sugiura Y. Neurotoxicity of petroleum benzine compared with n-hexane. Int Arch Occup Environ Health 1982;50:219-29.

5. Pryor GT, Bingham LR, Dickinson J, Rebert CS, Howd RA. Importance of schedule of exposure to hexane in causing neurotoxicity. Neurobehav Toxicol Teratology $1982 ; 4: 71-8$.

6. Rebert CS, Houghton PW, Howd RA, Pryor GT. Effects of hexane on the brainstem auditory response and caudal nerve action potential. Neurobehav Toxicol Teratology 1982;4:79-85.

7. Sandmeyer EE. Aliphatic hydrocarbons. In: Clayton GD, Clayton FE, ed. Patty's industrial hygiene and toxicology. New York, NY: John Wiley \& Sons, 1981: $3175-220$.

8. Takeuchi Y, Ono Y, Hisanaga N. An experimental study on the combined effects of n-hexane and toluene on the peripheral nerve of the rat. Br J Ind Med 1981;38:14-19.

9. Takeuchi Y, Ono Y, Hisanaga N, Iwata M, Aoyama M, Kitoh J, Sugiura Y. An experimental study on the combined effects of $\mathrm{n}$-hexane and methyl-ethyl ketone. Br J Ind Med 1983;40:199-203.

10. Takeuchi Y, Ono Y, Hisanaga N, Kitoh J, Sugiura $Y$. A comparative study on the neurotoxicity of n-pentane, $\mathrm{n}$-hexane, and $\mathrm{n}$-heptane in the rat. $\mathrm{Br} \mathrm{J}$ Ind Med 1980; $37: 241-7$.

11. Sanagi S, Seki Y, Sugimoto K, Hirata M. Peripheral nervous system functions of workers exposed to n-hexane at a low level. Int Arch Occup Environ Health 1980;47:69-79.

\section{Tetrahydrofuran}

1. Chabra RS, Elwell MR, Chou B, Miller RA, Renne RA. Subchronic toxicity of tetrahydrofuran vapors in rats and mice. Fund Appl Toxicol 1990;14:338 - 45 .

2. Emmett EA. Parosmia and hyposmia induced by solvent exposure. Br J Ind Med 1976;33:196-198.

3. Garnier R, Rosenberg N, Puissant JM, Chouvet JP, Efthymiou ML. Tetrahydrofuran poisoning after occupational exposure. Br J Ind Med 1989;46:677-8.

4. Juntunen J, Kaste M, Härkönen H. Cerebral convulsion after enfluran anaesthesia and occupational exposure to tetrahydrofuran. J Neurol Neurosurg Psychiatry 1984;47:1258.

5. Katahira T, Teramoto K, Horiguishi S. Experimental studies on repeated inhalation toxicity of tetrahydrofuran in rats. In: See LC, Peng LH, Fook CW, Nam $\mathrm{OC}$, ed. Proceedings of the tenth Asian conference on occupational health, Sept 5-10, Singapore; vol 2, $793-8$

6. Kawata F, Shimizu T, Ozono S. Determination and fluorescent histochemical approach to catecholamines in the rat brain after inhalation of tetrahydrofuran [in Japanese]. Nippon Hoigaku Zasshi 1986;40:821-3. (English abstract.)

7. Marcus RJ, Winthers WD, Hultin E. Neuropharmalogical effects induced by butanol, 4-hydroxybutyrate, 4mercaptobutyric acid thiolactone, tetrahydrofuran, pyrrolidine, 2-deoxy-d-glucose and related substances in the rat. Neuropharmacology 1976;15:29—38.

\section{Trichloroethylene}

1. Barret L, Garrel S, Danel V, Derbu JL. Chronic trichloroethylene intoxication: a new approach by trigeminal-evoked potentials? Arch Environ Res 1987; 47(5): $297-302$

2. Honma T, Sudo A, Miyagawa M, Sato M, Hasegawa H. Effects of exposure to trichloroethylene and tetrachloroethylene on the contents of acetylcholine, 
dopamine, norepinephrine and serotonin in rat brain. Ind Health 1980;18:171-8.

3. Isaacson LG, Spohler SA, Taylor DH. Trichloroethylene affects learning and decreases myelin in rat hippocampus. Neurotoxicol Teratology 1990;12:375-81.

4. Kyrklund $T$, Kjellstrand $P$, Hagild KG. Fatty acid changes in rat brain ethanolamine phosphoglycerides during and following chronic exposure to trichloroethylene. Toxicol Appl Pharmacol 1986;85:145-53.

5. Steward RD, Dodd HC, Gay HH, Erley DS. Experimental human exposure to trichloroethylene. Arch Environ Health 1970;20:64.

6. Veron RJ, Ferguson RK. Effects of trichloroethylene on visual-motor performance. Arch Environ Health $1969 ; 18: 894$.

\section{Tri-ortho-cresyl phosphate}

1. Byers PD, Brooks DM. Late changes in human muscles following triaryl phosphate poisoning. J Pathol Bacteriol 1967;93:37-45.

2. Prentice DE, Roberts NL. Acute delayed neurotoxicity in hens dosed with tri-o-cresyl phosphate (TOCP): correlation between clinical ataxia and neuropathological findings. Neurotoxicology 1983;4(2):271-6.

3. Smith MI, Lillie RD. The histopathology of tri-orthocresyl phosphate poisoning. Arch Neurol Psychiatry $1931 ; 26: 976-92$.

4. Susser M, Stein Z. An outbreak of tri-ortho-cresyl phosphate (TOCP) poisoning in Durban. Br J Ind Med 1957;14:111-26.

5. Somkuti SG, Tilson HA, Brown HR, Campbell GA, Lapadula DM, Abou-donia MB. Lack of delayed neu- rotoxic effect after tri-o-cresyl phosphate treatment in male Fischer 344 rats: biochemical, neurobehavioral and neuropathological studies. Fund Appl Toxicol 1988;10:199-205.

\section{Vinyl chloride}

1. Dinceva E, Kolev P, Dalbokova D. EEG changes in workers with prolonged exposure to a mixture of organic solvents and vinyl chloride. Higiena zdraveopazvane $1986 ; 29: 8-15$.

2. Langauer-Lewowicka $\mathrm{H}$, Kurzbauer $\mathrm{H}$, Byczkowska Z, Wocka-Marek T. Vinylchloride disease neurological disturbances. Int Arch Occup Environ Health 1983;52: $151-7$.

3. Nicholson WJ, Henneberger PK, Seidman H. Occupational hazards in the VC-PVC industry. Prog Clin Biol Res 1984;141:155-75.

4. Perticoni GF, Abbritti G, Cantisani TA, Bondi L, Mauro L. Polyneuropathy in workers with long exposure to vinyl chloride: electrophysiological study. Electromyogr Clin Neurophysiol 1986;26:41 -7.

5. Sinczuk-Walczak H, Gluszcz M. Various aspects of the clinical and electroencephalographic studies in workers occupationally exposed to vinyl chloride. Med Pr 1982;33:349-354.

6. Suciu I, Prodan L, Ilea E, Paduraru A, Pascu L. Clinical manifestations in vinyl chloride poisoning. Ann NY Acad Sci 1975;246:53-69.

Received for publication: 28 December 1992 